\title{
Investigation of Microstructure and Creep Properties of Sn-xSb Solder Alloys up to Peritectic Composition
}

\author{
R. Afify Ismail, A.M. Yassin, B.A. Khalifa \\ Redaafify@sci.asu.edu.eg, amalyassin477@gmail.com, b.khalifa@sci.asu.edu.eg
}

\begin{abstract}
Particle strengthening was studied in $\mathrm{Sn}-\mathrm{xSb}(\mathrm{x}=0.5-3.0 \mathrm{wt}$. \%). Tensile deformation behavior of $\mathrm{Sn}-2.5 \mathrm{wt} . \%$ $\mathrm{Sb}$ is investigated at temperature ranging $(298-343 \mathrm{~K})$ and under different constant loads ranging $(5.1-14.0$ $\mathrm{MPa}$ ). The microstructure characteristics of the tested alloys have been obtained using x-ray diffraction. Morphological studies using optical microscope have been investigated to obtain correlation between the microstructure and mechanical behavior of the alloys. The improved strength is attributed to the uniform distribution of the SnSb intermetallic compound (IMC) inside $\beta$-Sn matrix. Based on the obtained stress exponent $(n)$ and activation energy $(\mathrm{Q})$, it is proposed that the dominant deformation mechanism is dislocation climb over the whole temperature range used.
\end{abstract}

KEYWORDS: Lead-free solder, Sn-Sb alloys, microstructure, creep properties.

\section{INTRODUCTION}

Owing to the realization of the harmful effect of Lead $(\mathrm{Pb})$ and $\mathrm{Pb}$-containing alloys on the environment and human health, many $\mathrm{Pb}$-free solder alloys (LFS) have been developed to replace $\mathrm{Sn}-\mathrm{Pb}$ solders in electronic applications [1]. In last decade, Au-20 wt.\% Sn is considered as the best solder alloy for applications in optoelectronic packaging, because of its high creep resistance, wetabillity, and good reliability [2]. This solder alloy is expensive and has high melting temperature $\left(280^{\circ} \mathrm{C}\right)$ which could damage the properties of optical fibers and optoelectronics such as lasers, light emitting devices, photo detectors, or waveguide devices $[3,4]$. Now many numbers of (LFS) such as $\mathrm{Sn}-\mathrm{Zn}, \mathrm{Sn}-\mathrm{Cu}, \mathrm{Sn}-\mathrm{Ag}$ and $\mathrm{Sn}-\mathrm{Au}$ have been developed. Recently $\mathrm{Sn}-\mathrm{Sb}$ solder alloys are consider as an attractive candidate of (LFS) when compared to Sn-Au [5-8]. The interest on the near pertiectic SnSb (LFS) have received considerable attention for high temperature electronic application specially on step soldering technology, optical devise packing and flip - chip packaging, etc. [9-11]. SnSb near peritectic compositions have advantages of better room temperature creep resistance, ductility, higher microstructure stability and superior tensile strength compared with SnPb solder [12-17]. The creep studies of $\mathrm{SnSb}$ alloys have received a great deal attention [18-23]. The knowledge of creep behavior of SnSb alloy under long term mechanical loading is essential for evaluation of their severe life time [10]. The aim of the present work is concerned with the effect of $\mathrm{Sb}$ content and working temperature on the microstructure development and creep properties of Sn-Sb solder alloys.

\section{EXPERIMENTAL PROCEDURE}

The Sn- $x$ Sb (where, $x=0.5-3.0 w t$. \%) were prepared from Sn and Sb elements with purity $99.99 \%$ and melted in high purity clean graphite crucible. The ingot solder was cast in iron mold to produce rode-like with diameter of $10 \mathrm{~mm}$. The ingots were cold drawn to wire samples of $0.7 \mathrm{~mm}$ diameters. To obtain samples containing fully precipitated phases, the samples were homogenized at $433 \mathrm{~K}$ for 48 hours and slowly cooled to room temperature. The alloy samples were annealed at $423 \mathrm{~K}$ for two hours and slowly cooled to room temperature with a cooling rate of 0.1 degree/min. Creep test of samples was carried out by using a computerized tensile creep testing machine [24]. The microstructure of samples were observed by optical microscope (Nikon XN - Japan) after a mechanical polishing using a sand paper followed by an abrasive - free micro cloth until a bright surface is obtained. Etching with a solution of $10 \% \mathrm{HCl}, 40 \%$ Ethyl alcohol and $50 \%$ $\mathrm{HNO}_{3}$; at room temperature for $120 \mathrm{sec}$, followed immediately by washing in a rapid running water and dried by filter paper. Samples were analyzed by $x$-ray diffraction (XRD) using Philips $X^{\prime}$ Pert (MPD) goniometer 
PW3050/00 with graphite monochromatic using $\mathrm{Cu}-\mathrm{K}_{\alpha}$ target and $\mathrm{Ni}$ filter operated at (40 K.V.) and (30 mA) to give radiation of wavelength $(\lambda=0.15406 \mathrm{~nm})$ was used in $2 \theta$ rang $\left(25-85^{\circ}\right)$.

\subsection{Effect of Sb-element wt. \%.}

In this research, Sn-xSb with different Sb contents $(x=0.5,1.0,1.5,2.0,2.5,3.0$ wt. \%) were studied using creep test machine at constant applied stress $11.7 \mathrm{MPa}$ and at room temperature. The diameter of the grain size of each composition was measured using a special scale photographed by digital camera fitted in the optical microscope.

\subsection{Effect of working temperatures}

Creep tests were performed on Sn-2.5wt.\%Sb alloys at working temperature range (298 -343K) and under different constant loads ranging (5.1 - 14.0 MPa). The temperatures were monitored using a thermocouple in contacting with the specimens within an accuracy of $1^{\circ} \mathrm{C}$.

\section{RESULTS AND DISCUSSIONS}

\subsection{Microstructures}

\subsubsection{X-ray diffraction analysis}

\subsection{1a) Effect of xSb wt.\% content on the microstructure}

Fig. 1(a) shows the XRD profile of the $\mathrm{Sn}-\mathrm{xSb}(\mathrm{x}=0.5-3.0 \mathrm{wt} \%)$ solders crept at room temperature (298K) and under constant applied stress (11.7 MPa). Intense peaks of $\beta$-Sn rich phase besides some profiles of SnSb IMCs have been observed. It is well known that the SnSb (IMCs) are formed in the $\beta$-Sn matrix during solidification [25].

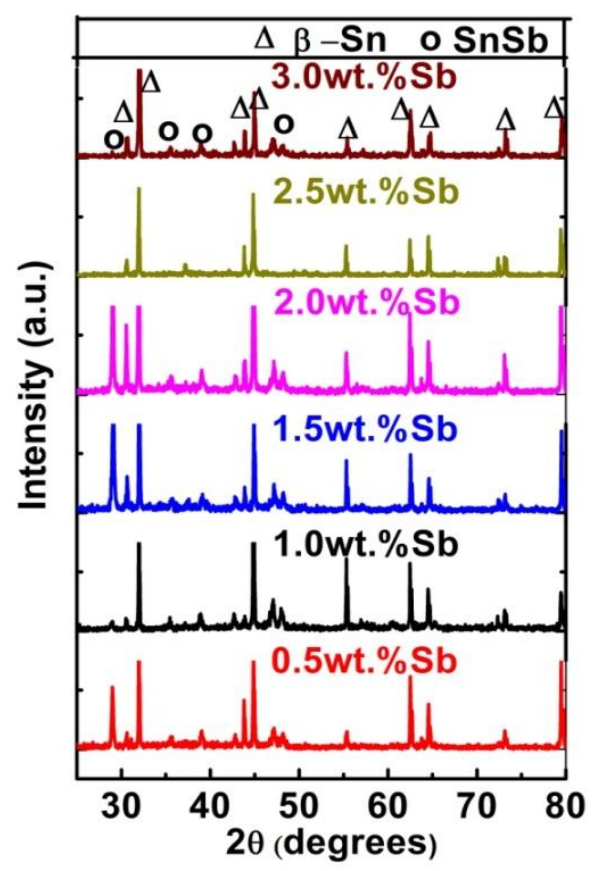

Figure 1(a): X-ray diffraction patterns for $\mathrm{Sn-xSb}(\mathrm{x}=0.5,1.0,1.5,2.0,2.5,3.0$ wt.\%) solder alloys crept at room temperature $(298 \mathrm{~K})$ and under constant applied stress $(11.7 \mathrm{MPa})$.

It should be pointed out that the diffraction lines of SnSb IMCs appeared at low content $(0.5 \% \mathrm{Sb})$ increased at $1.5 \%$ and $2.0 \% \mathrm{Sb}$ alloys, then decreased at higher contents $(2.5 \%, 3.0 \% \mathrm{Sb})$. Fig. $\mathbf{1}(\mathbf{b}, \mathbf{c})$ shows $\mathrm{x}$-ray lattice 
parameters (a \& c) of $\beta$-Sn rich phase as a function of $\mathrm{Sb} w t . \%$. It is obvious from the figure that the lattice parameters are slightly changed except at $2.0 \mathrm{wt}$. \%Sb composition.
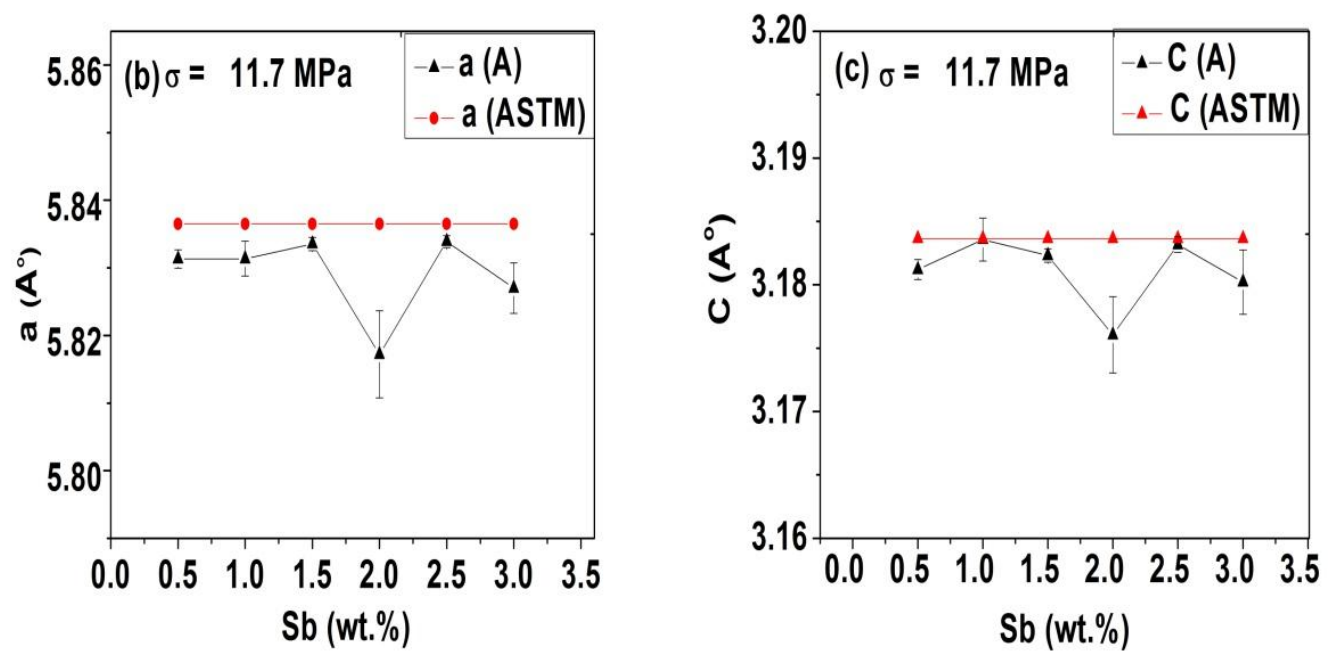

Figure 1(b, c): The lattice parameters $(a \& c)$ of $\beta-S n$ rich phase as a function of Sb wt.\%

Fig. 1(d) shows the variation of peak height intensities of some crystallographic planes [(200), (211)] follow the same behavior of lattice parameters. The apparent crystallite size (L) normal to (101) plane was calculated from half maximum full width (HMFW-B) according to Sherrer equation [24].

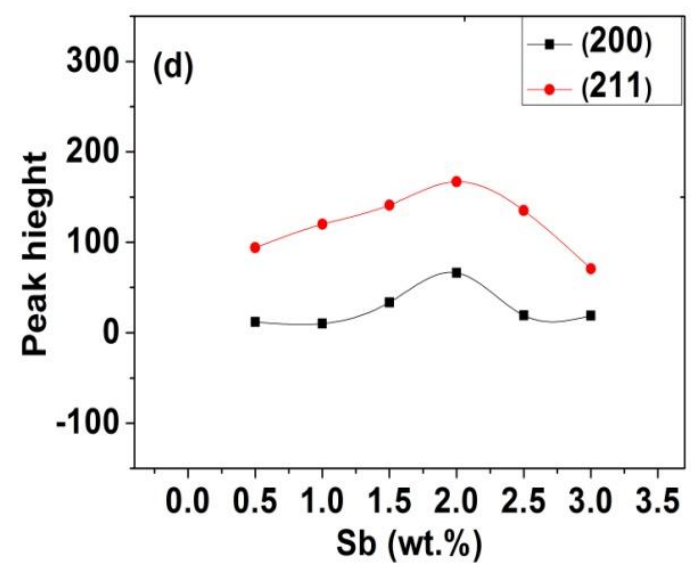

Figure 1 (d): The intensities of crystallographic planes [(200) \& (211)] as a function of Sb wt.\%

$L=K \lambda / B \cos \theta$

Where, $\mathrm{K}$ is the Sherrer parameter equal to (0.9) for (HMFW). The relation between crystallite size and Sb wt.\% is shown in fig.1(e). The results show an agreement with $\mathrm{x}$-ray parameters. The significant change at $2.0 \mathrm{wt} . \%$. $\mathrm{Sb}$ can be attributed to the maximum cluster of SnSb intermetallic compound. 


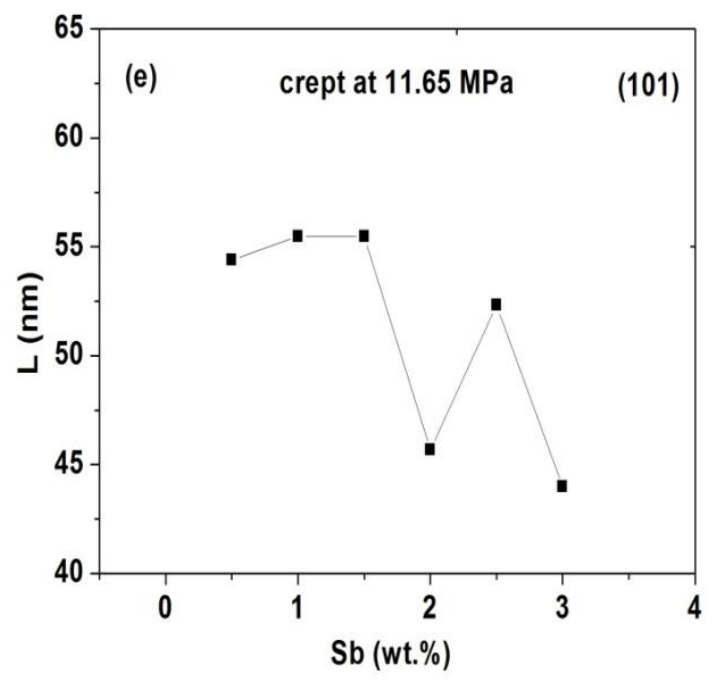

Figure 1(e): The apparent crystallite size of (101) plain of solder alloy as a function of Sb wt.\%.

\subsection{1b) Effect of working temperatures on the microstructure}

Fig.2(a) shows the XRD patterns of Sn-2.5wt.\%Sb crept at 7.6 MPa and at five different working temperatures ranged from (298-343 K).

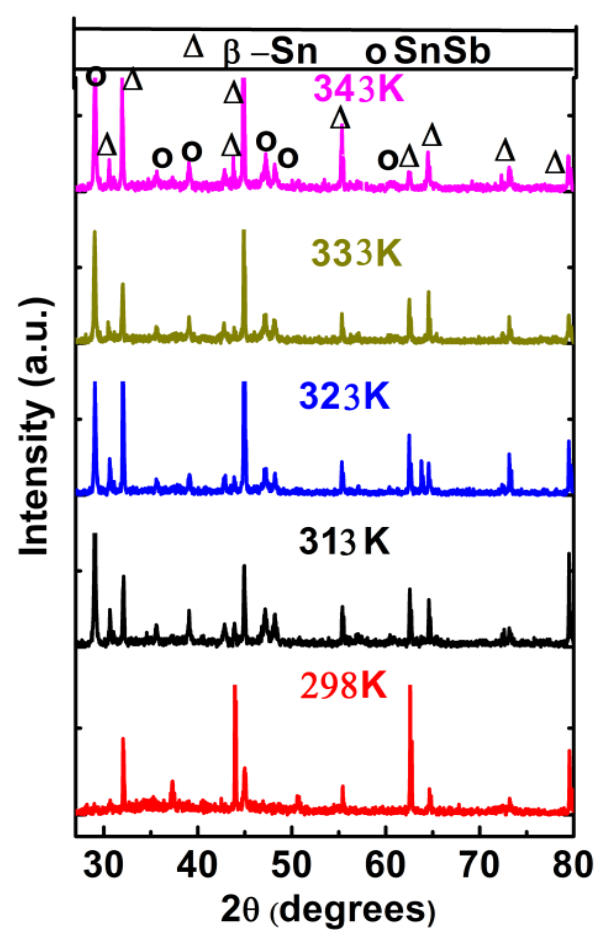

Figure 2(a): X-ray diffraction patterns for Sn-2.5wt.\%Sb alloy crept at 7.6 MPa and at different working temperatures. 
Fig. $\mathbf{2}(\mathbf{b}-\mathbf{c})$ shows that the lattice parameters $(a \& c)$ are slightly changed with temperature except at $323 \mathrm{~K}$.
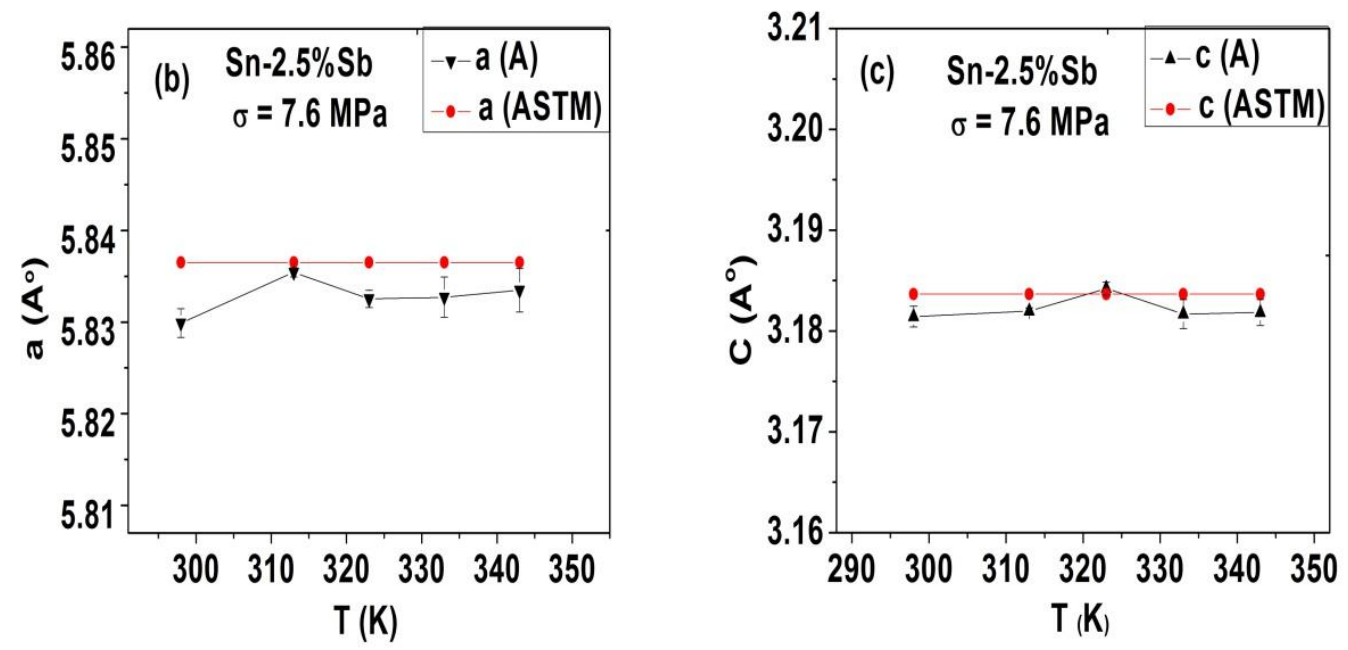

Figure $2(b, c)$ : The lattice parameters (a \& c) for Sn-2.5wt.\%Sb alloy crept at $7.6 \mathrm{MPa}$ as a function of different working temperatures.

The intensities of the planes (101), (301) are illustrated in fig. 2(d). The crystallite size $L$ normal to the (101) plane as a function of working temperature is in agreement with the other $x$-ray parameters [Fig. 2(e)]. It can be seen that the $\beta$-Sn matrix and SnSb phase are the main constitutes in the near peritectic solder alloy; the results are in agreement with other reported references [26].
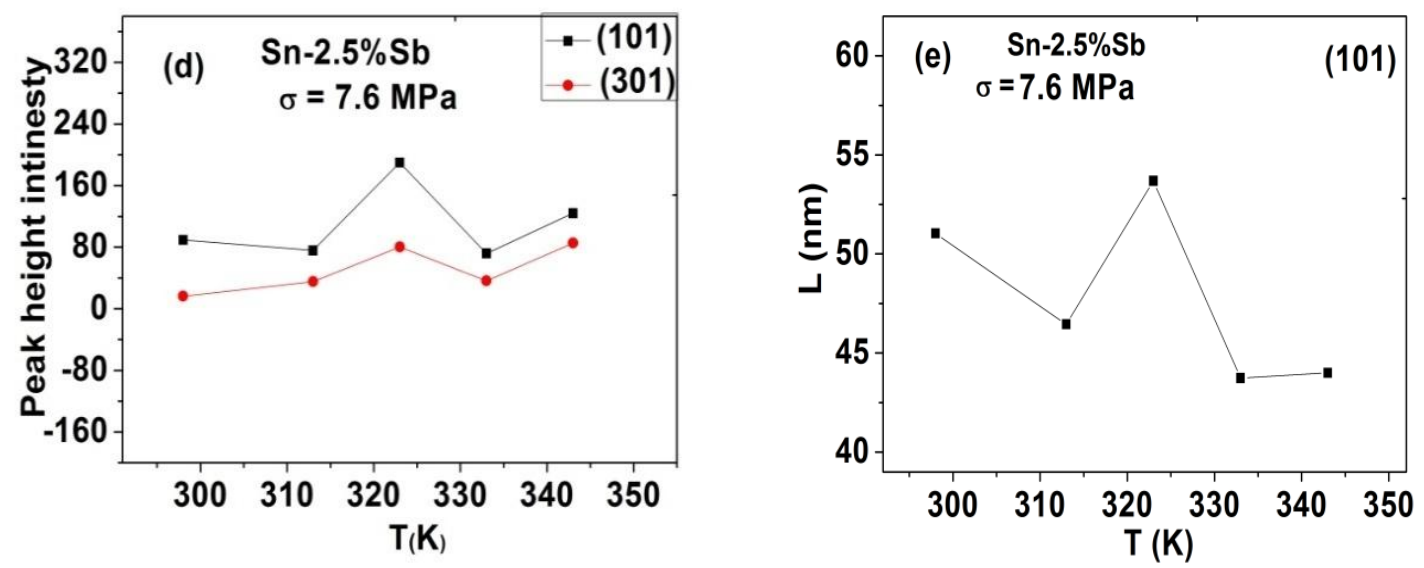

Figure 2 (d,e): The intensities of the crystallographic planes [(101) \& (301)] and the apparent crystallite size of (101) plane of Sn-2.5wt.\%Sb alloy as a function of working temperatures.

\subsubsection{Morphological studies}

Microstructure evaluation plays an important rule to explain the mechanical properties of SnSb alloys. Optical microscope images of $\mathrm{Sn}-\mathrm{xSb}$ solder alloys show decrease of the equiaxed grains from $116 \mu \mathrm{m}$ to $31 \mu \mathrm{m}$ with increasing the $\mathrm{Sb}$ wt.\% except at $2.0 \mathrm{wt}$.\%Sb solder. The $\mathrm{SnSb}$ (IMC) is distributed inside $\beta$-Sn matrix as shown 
in fig. 3(a-f). Clustering of SnSb (IMC) developed at $1.5 \mathrm{wt} \% \mathrm{Sb}$ until $2.5 \mathrm{wt} . \% \mathrm{Sb}$ showing a maximum aggregation at $2.0 \mathrm{wt} . \% \mathrm{Sb}$ [fig.3 (c-e)].
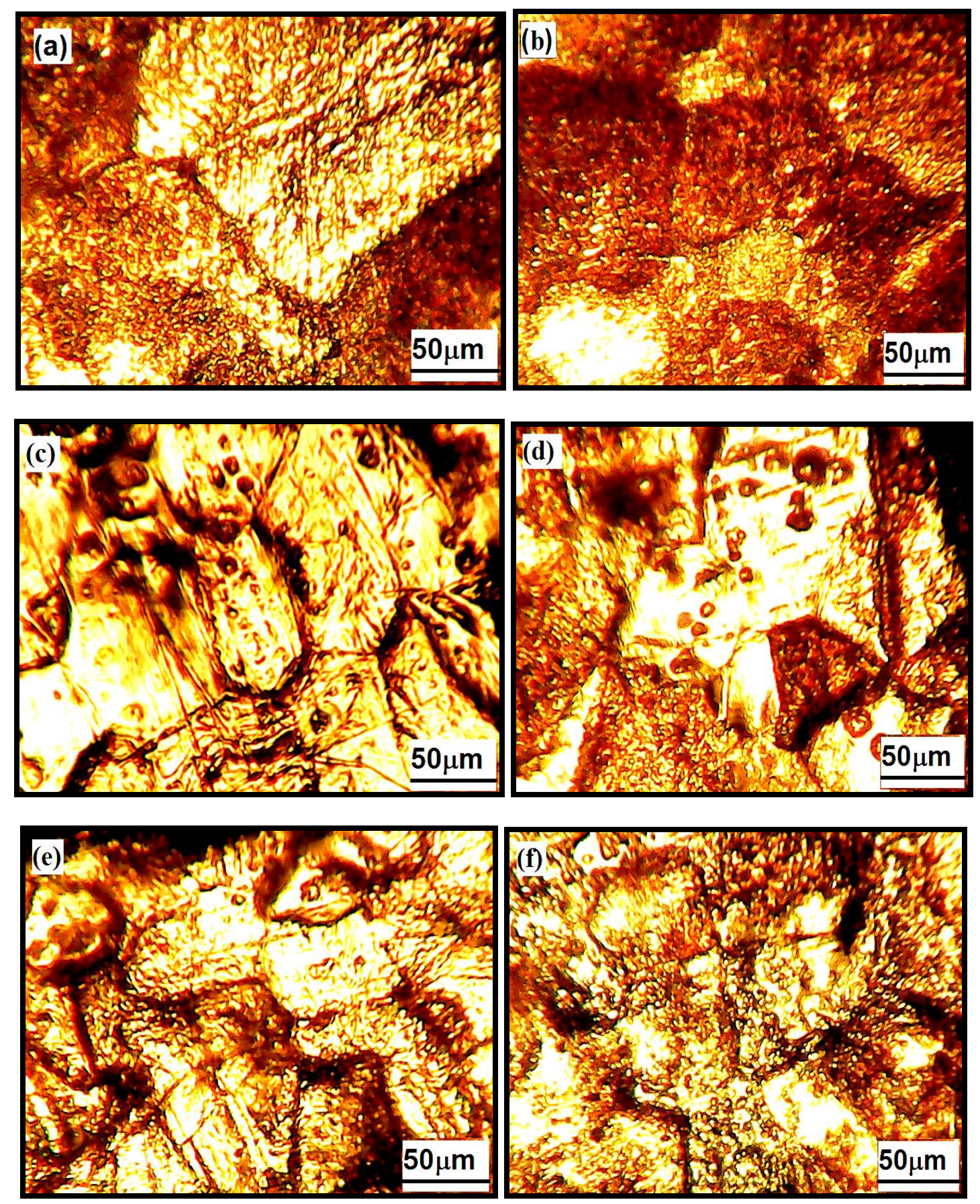

Figure 3: OM microstructures of (a) Sn-0.5Sb, (b) Sn-1.0Sb (c) Sn-1.5Sb (d) Sn-2.0Sb (e) Sn-2.5Sb (f) Sn3.0Sb solder alloys respectively. 


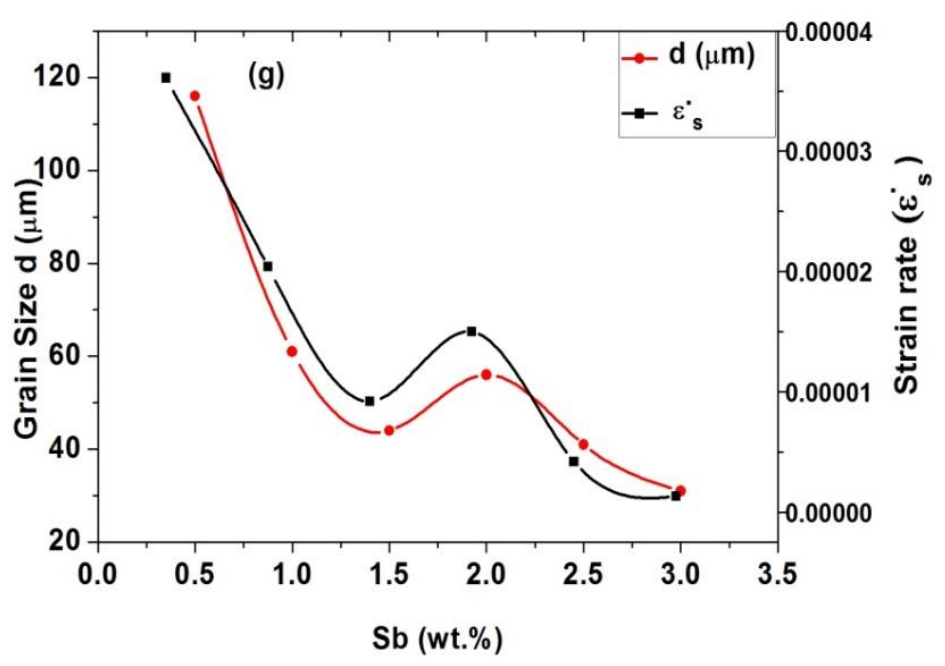

Figure 3 (g): The relation between grain diameter (d) and strain rate as a function of Sb wt. \%.

The average grain diameter and steady state strain rate are decreased with $\mathrm{Sb}$ wt.\% except at $2.0 \mathrm{Sb}$ wt.\% as shown in fig $\mathbf{3} \mathbf{( g )}$, which are in agreement with all $\mathrm{x}$-ray parameters.

\subsection{Tensile properties}

\subsubsection{Effect of Sb-content (composition effect) on the creep behavior}

Tensile creep tests for the six solders Sn-x wt.\% Sb where $(x=0.5-3.0$ wt. \%) were carried out at room temperature $(298 \mathrm{~K})$ under constant applied stress (11.7 MPa) are represented in fig. 4(a).

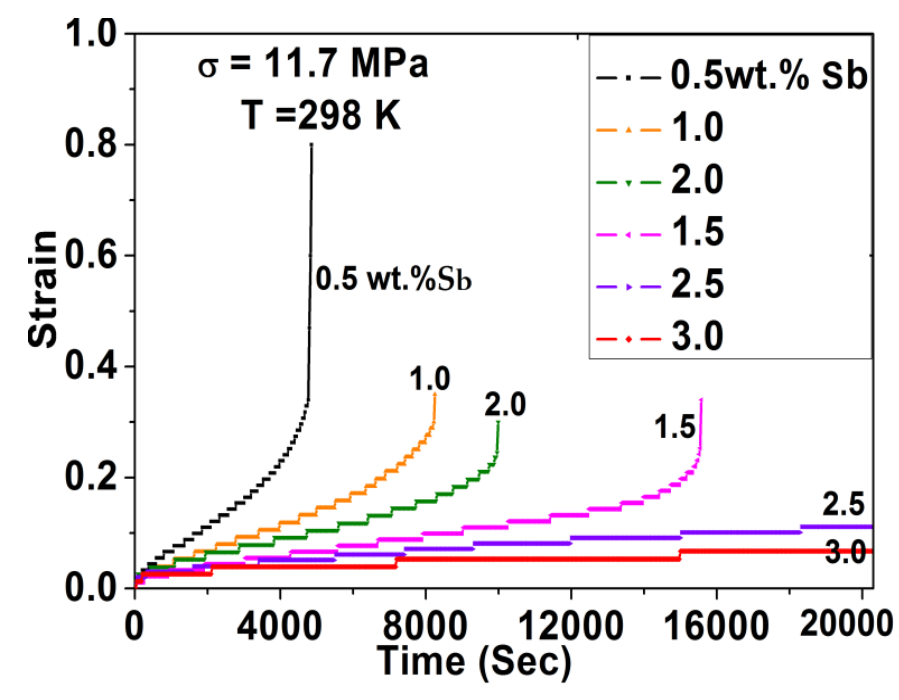

Figure 4(a): Creep behavior of $\mathrm{Sn}-\mathrm{xSb},(\mathrm{x}=0.5,1.0,1.5,2.0,2.5,3.0)$ solder alloys crept at $11.7 \mathrm{MPa}$ and $298 \mathrm{~K}$. 
Among the alloys investigated, Sn-2.5wt.\% Sb and Sn-3wt.\% Sb exhibits the best creep resistance. Fig. $\mathbf{4 ( \mathbf { b } )}$ illustrates the variation of min. creep rate as a function of $\mathrm{Sb}$ - content. The figure shows anomalous effect at 2.0wt.\% Sb which is in agreement with x-ray parameters due to the maximum clustering of the SnSb (IMCs) [fig. 3 (d)]. The correlation between creep properties and microstructure is very important as the creep strength is dependent on the microstructure evolution which is in turn affected by alloy composition. The $\mathrm{Sn}$ rich corner of Sn-Sb phase diagram is illustrated in fig.4(c) [26].

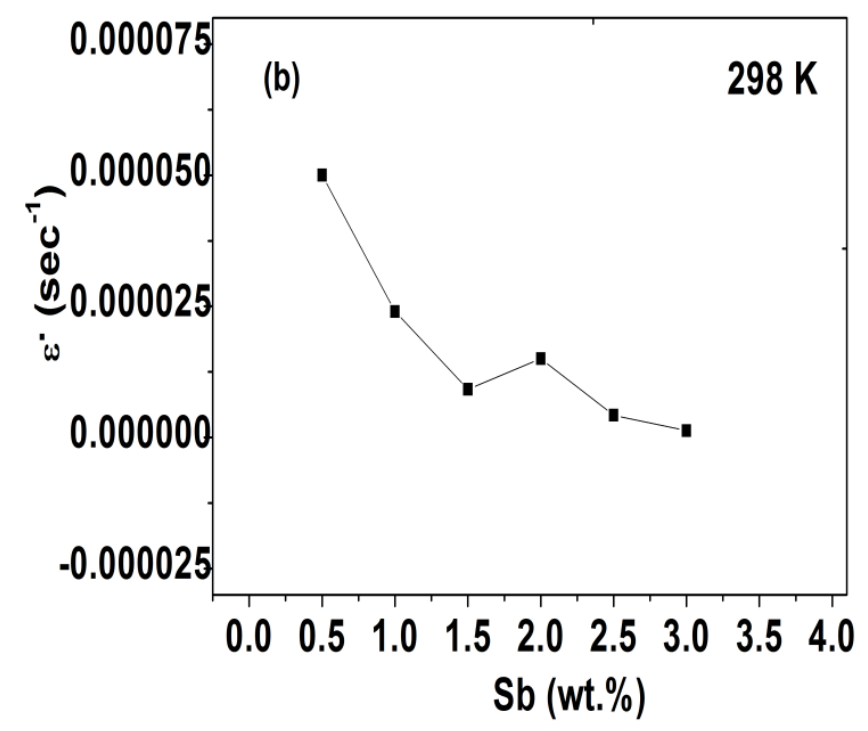

Figure 4(b): The min. creep rate as a function of $\mathrm{Sb} w t . \%$.

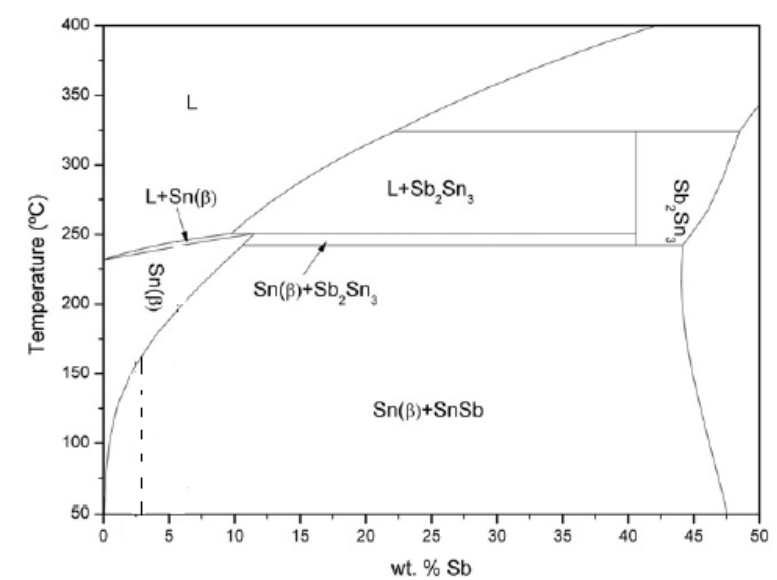

Figure 4(c): Sn-Sb equilibrium phase diagram [26].

\subsubsection{Effect of working temperatures on the creep of Sn-2.5 wt.\% Sb alloy.}

Creep results for Sn-2.5wt.\%Sb alloy were carried out at different temperature ranges (298 - 343K) and under different constant applied stresses from (5.1 - $14.0 \mathrm{MPa})$. Fig.5 (a,b,c) shows creep results for Sn-2.5\%Sb alloy samples crept at 298, 313 and $343 \mathrm{~K}$ (as examples). From the figures, it is noted that while stress and temperature were increasing, the duration of time to fracture decreased. Moreover, the creep - strain curves are regularly arranged with the increase of both temperature and stress. 

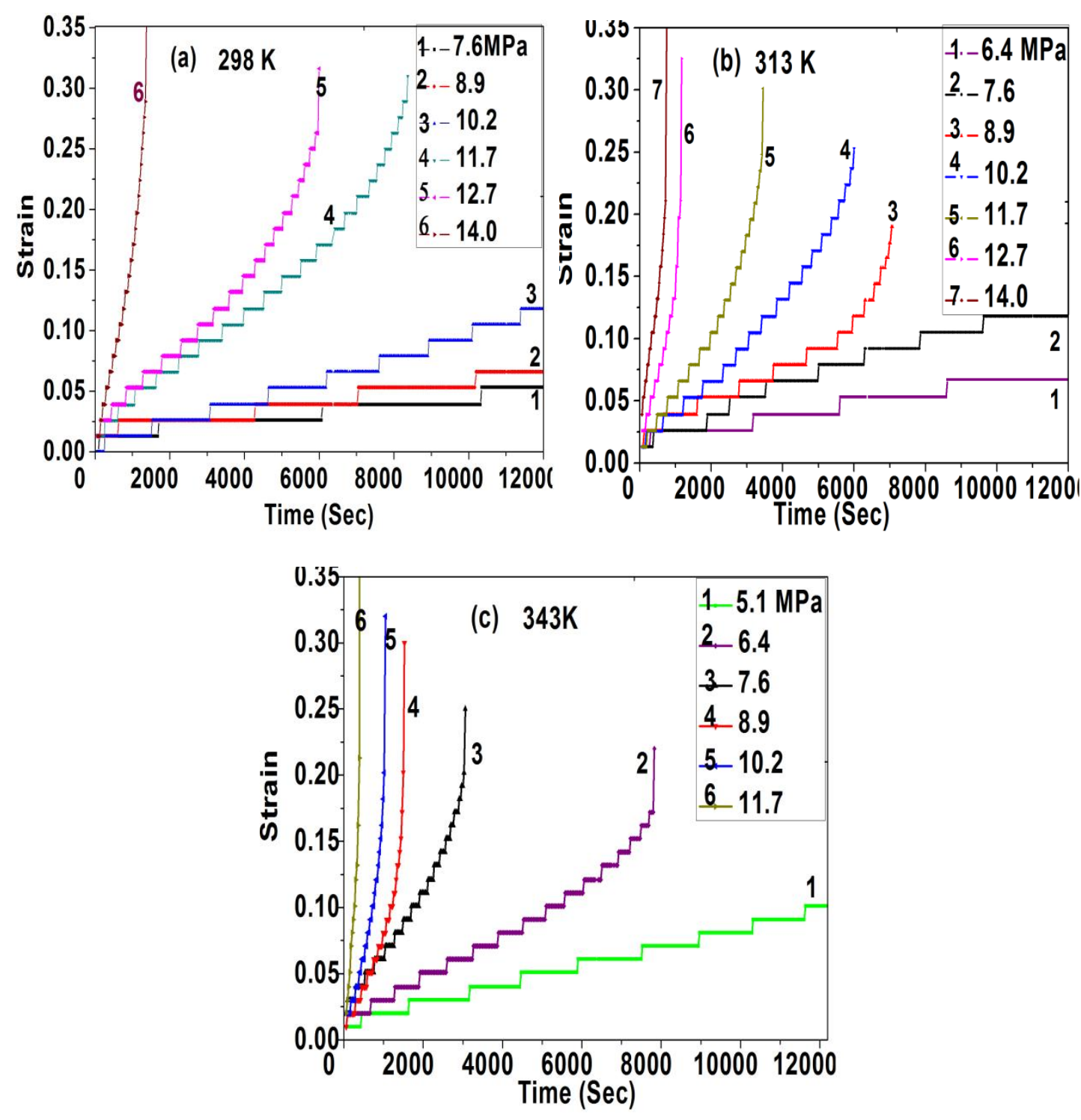

Figure 5 (a, b, c): Creep behavior of Sn-2.5wt.\%Sb solder material at 298, 313 and 343K and different applied stresses.

The slopes of linear parts of these curves known as steady state-strain rate $\left(\varepsilon_{s}\right)$ are dependent on both applied stresses and creep temperatures. Fig. 5(d) shows the dependence of the creep rate on time [as an example at $(\mathrm{T}=343 \mathrm{~K})]$. The three stages (transient, steady and fracture) are also illustrated. Fig. 5(e) represents the relationship between strain and time for $\mathrm{Sn}-2.5 \mathrm{wt}$. \% Sb alloy crept at $7.6 \mathrm{MPa}$ (as an example) at different working temperatures. 

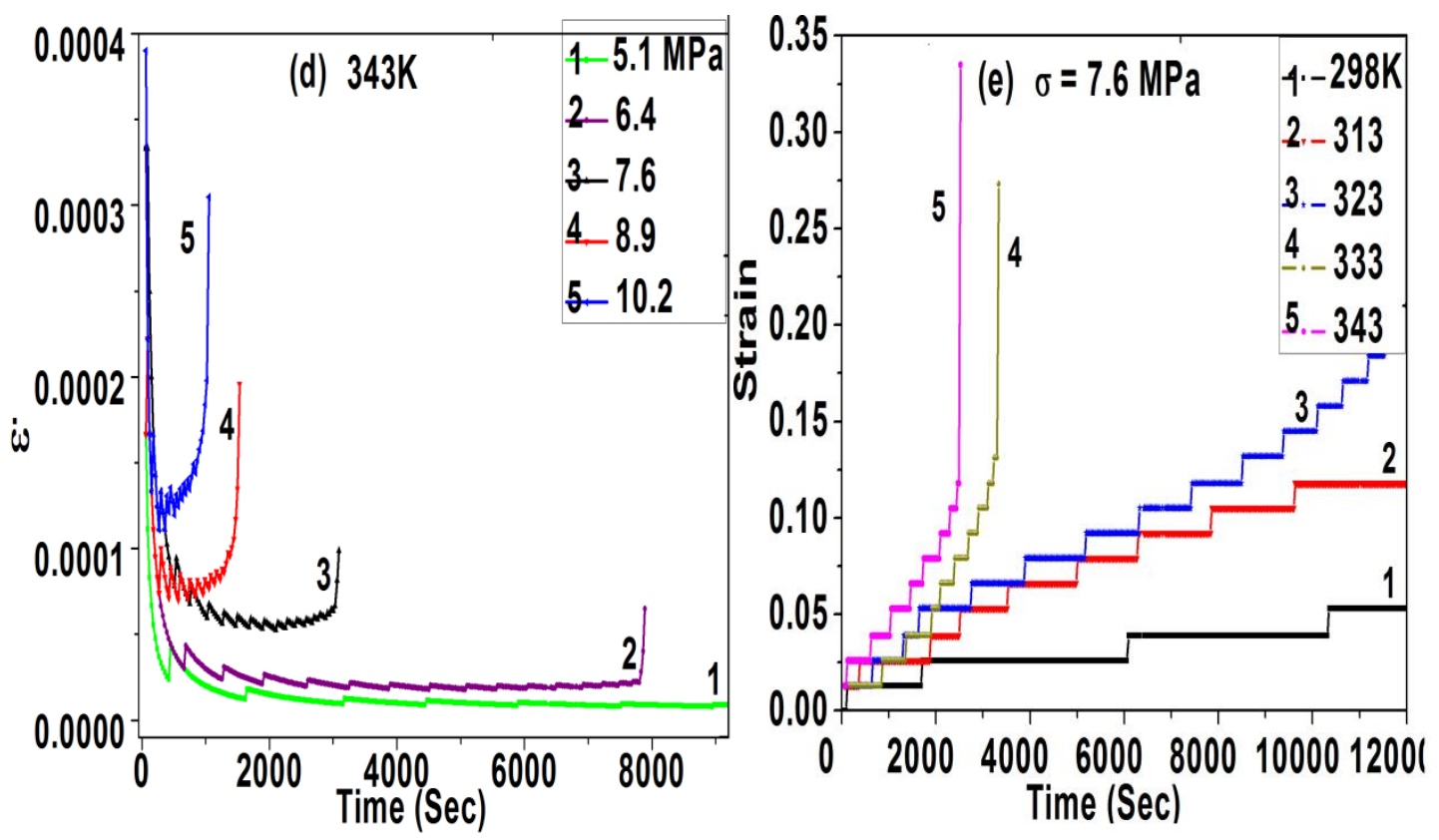

Figure $5(\mathrm{~d}, \mathrm{e})$ : Creep rate - time relationship and creep behavior for the crept alloy at 7.6MPa and different working temperature.

\subsection{Creep stress exponents and activation energies}

Creep deformation mechanisms of Sn-2.5wt.\%Sb solder is identified by two important parameters ( $\mathrm{n}$ and Q). The investigation of this alloy relating strain rate, temperature and activation energy with stress during creep deformation is characterized using previous studies [24] indicated; that the dependence of steady state creep rate $\varepsilon_{s}$ on the applied stress $(\sigma)$ and temperature $\mathrm{T}$ can be expressed as:

$\varepsilon_{s}=A \sigma^{n} \exp (-Q / R T)$

Where $\mathrm{A}$ is a complex constant depends on the material structural properties. Taking the natural logarithm on both sides of equation (3), we get:-

$\ln \varepsilon_{s}=\ln A+n \ln \sigma-Q / R T$

It is clear that at a given temperature the creep stress exponent (n) can be calculated by linear regression of the experimental data. It is assumed that the deformation is dominant by one creep mechanism in the whole stress range applied; therefore the stress exponent can be taken as a constant at any given temperature. Fig. 6(a) shows linear relationships between $\left(\ln \varepsilon_{s}\right.$ and $\ln \sigma$ ) The relationship between the exponents (n) as a function of working temperatures is shown in fig. $\mathbf{6 ( b )}$. 

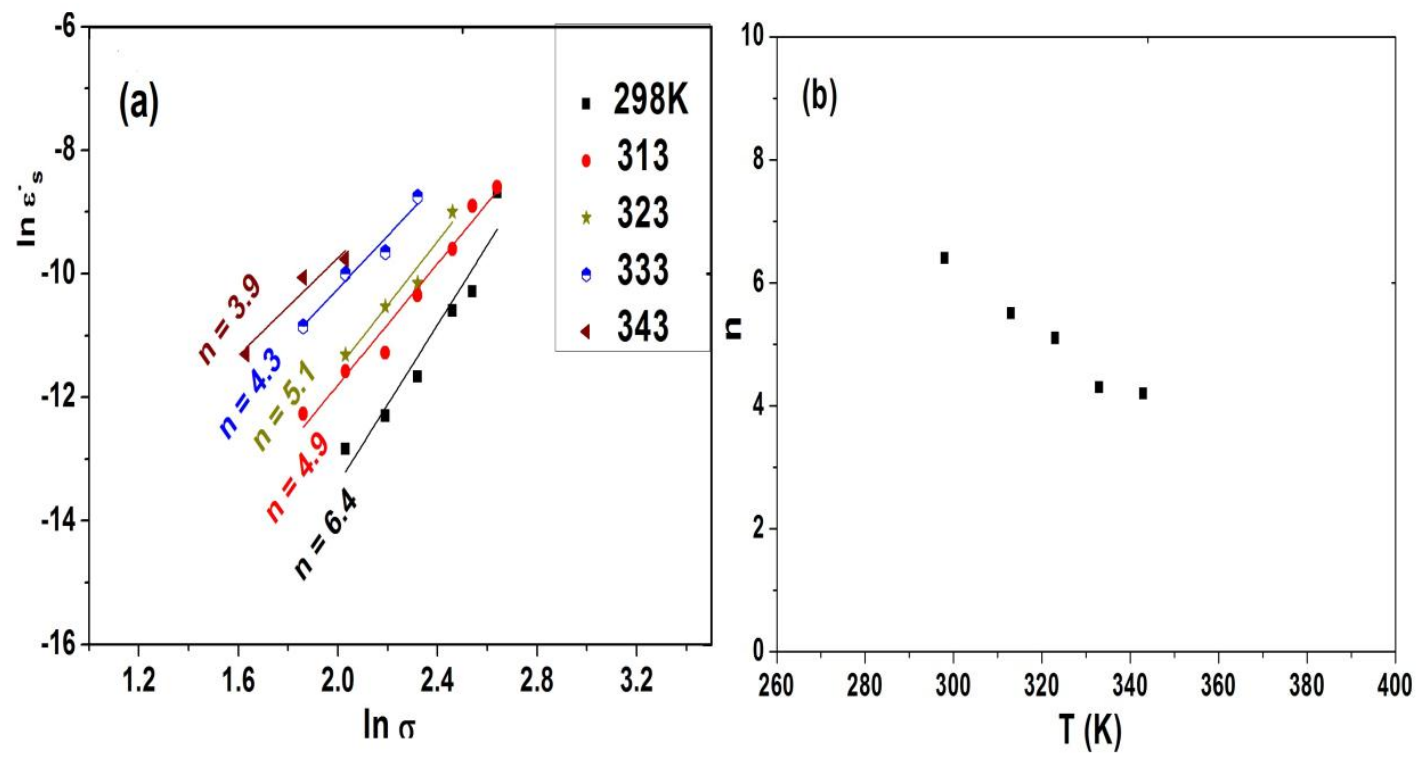

Figure $6(\mathbf{a}, \mathbf{b})$ : Relationships between $\ln \varepsilon_{s}$ and $\ln \sigma$ and the relationship between $\mathbf{n}$ and $\mathbf{T}(\mathbf{K})$.

The relation $\left(\ln \varepsilon_{s}\right.$ and $\left.1 / T\right)$ is represented in fig. 7. The creep parameters of the present alloy at different applied stresses ( $n, Q$ ) values are varied from 3.9 to 6.4 and from 51.2 to $62.9 \mathrm{KJ} / \mathrm{mol}$ respectively. These values are complied with the reported values of $(\mathrm{Sn}-\mathrm{Sb})$ which is controlled by dislocation climb $[\mathbf{2 3}, \mathbf{2 7}, \mathbf{2 8}$.

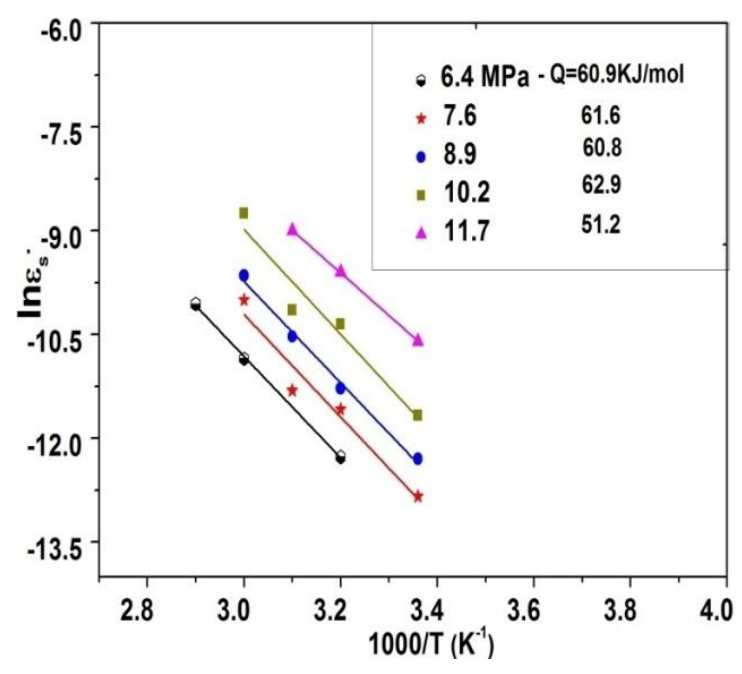

Figure 7: Linear relationships between $\left(\ln \varepsilon_{s}\right.$ and $\left.1 / T\right)$ for Sn-2.5wt.\%Sb alloy crept at different applied stresses

\section{CONCLUSIONS}

The following conclusions can be drawn from the present study: 
Creep strain tests conducted on Sn-xSb solder alloys, where $(x=0.5-3.0$ wt.\%) were carried out under constant applied stress (11.7 MPa) at room temperature (298 K). and on Sn-2.5wt.\% Sb solder alloy under different applied stresses $(5.1-14.0 \mathrm{MPa})$ at three working temperatures $(298,313$ and $343 \mathrm{~K})$, in order to study the essential creep behavior of the solder bulk materials.

1) X-ray investigations of the crept samples with different compositions show the formation of $\mathrm{SnSb}$ (IMCs) distributed throughout $\beta$-Sn matrix.

2) Anomalous change in the $\mathrm{x}$-ray parameters is detected for Sn-2.0wt.\% Sb composition which is confirmed by the maximum clustering of the SnSb (IMCs) is shown in the optical micrographs. This is confirmed by the changes in both grain size and steady state strain rate with $\mathrm{Sb} w \mathrm{wt} \%$.

3) Morphological studies showed that $\beta$-Sn grain size decreased by increasing the $\mathrm{Sb}$ - content, whereas $\mathrm{SnSb}$ (IMCs) start to cluster at $1.5 \mathrm{wt}$.\%Sb with a maximum values at $2.0 \mathrm{wt} . \% \mathrm{Sb}$.

4) For Sn-2.5wt.\% Sb samples crept under constant applied stress (7.6 MPa) and different working temperatures, the $\mathrm{x}$-ray parameters exhibits a peak at $323 \mathrm{~K}$.

5) $\mathrm{Sn}-2.5 \mathrm{wt} . \% \mathrm{Sb}$ and $\mathrm{Sn}-3.0 \mathrm{wt} . \% \mathrm{Sb}$ solder alloys exhibit the best creep resistance.

6) The creep stress exponent ( $n$ ) and activation energy (Q) values calculated for Sn-2.5wt.\%Sb lead free solder alloy from the steady state creep region fall well within the scope of other published data, where the proposed deformation mechanism is dislocation climb over the whole temperature range investigated.

\section{REFERENCES}

1. A.K. Gain, T. Fouzder, Y.C. Chan, A. Sharif, N.B. Wong, W.K.C. Yung, "The influence of addition of Al nano-particles on the microstructure and shear strength of eutectic $\mathrm{Sn}-\mathrm{Ag}-\mathrm{Cu}$ solder on $\mathrm{Au} / \mathrm{Ni}$ metallized Cu pads", J. Alloys and compounds, 506, (2010), 216-223.

2. G.S. Zhang, H.Y. Jing, L.Y. Xua, J. Wei, Y.D. Han, creep behavior of eutectic $80 A u / 20$ Sn solder alloy, J. Alloy. compd., 476 (2009) 138-141.

3. S. Kang, A. Sarkhel, "Lead (Pb)-free solders for electronic packaging", J. Electron Mater., 23 (8) (1994) 701-707.

4. A.N. Fouda, E.A. Eid, "Inflounce of $\mathrm{ZnO}$ nano-particles addition on thermal analysis microstructure evaluation and tensile behavior of Sn-5.0 wt.\%Sb-0.5wt.\%Cu lead -free solder alloy", Mater. Sci. Eng., A 632 (2015) 82-87.

5. B.A. Khalifa and R. Afify Ismail, "Effect of Heat Treatment on the Mechanical and Microstructure of Sn3wt.\%Sb Alloy", International Journal of Materials Science, vol. 8, 1 (2013) 45-56.

6. I. Shohji, Y. Toyama, "Effect of strain rate on tensile properties of miniature size specimens of several lead-free alloys", Materials Science Forum, 783-786 (2014) 2810-2815.

7. K. Kobayashi, I. Shohji, H. Hokazono, "Tensile and fatigue properties of miniature size specimens of Sn5Sb lead-free solder", Materials Science Forum, Vol. 879 (2016) 2377-2382.

8. K. Kobayashi, I. Shohji, S. Koyama, H. Hokazono, "Fracture Behaviors of Miniature Size Specimens of Sn-5Sb Lead-Free Solder under Tensile and Fatigue Conditions", Procedia Engineering, 184, (2017) 238 -245 . 
9. R.M. Shalaby, J. Alloys Compd. 480 (2009) 334-339.

10. A.A. El-Daly, Y. Swilem, A.E. Hammad, J. Alloys Compd., 471 (2009) 98-104.

11. R. Novakovic, D. Giuranno, E. Ricci, S. Delsante, D. Li, G. Borzone, Surface Sci., 605 (2011) 248-255.

12. G. Zeng, S. Xue, Zhang, L. Gao, J. Mater. Sci. Mater. Electron., 22 (2011)565-571.

13. S.K. Das, A. Sharif, Y.C. Chan, N.B. Wong, W.K.C. Yung, J. Alloys Compd., 481(2009) 167-172.

14. A.A. El-Daly, A.E. Hammad, Mater. Sci. Eng. A, 527 (2010) 5212-5219.

15. A.A. El-Daly, A.E. Hammad, J. Alloys Compd., 505 (2010) 793-800.

16. F.X. Che, W.H. Zhu, S.W. Edith, X.W. Poh, X.R. Zhang, X.W Zhang, J. Alloys Compd., 507 (2010) 215-224.

17. A.M. Yassin, R.L. Reuben, G. Saad, M.H.N. Beshai, and S.K. Habib, "effect of annealing and microstructure on the creep behavior of an Sn-10wt.\% Sb alloy", Proc. Inst. Mech. Eng., vol.213, part 1 (1999) 59-68.

18. K.L. Murty, F.M. Haggag, and R.K. Mahidhara, J. Electron. Mater., 26 (1997) 839.

19. P.T. Vianco and D.R. Frear, JOM, 45(7) (1993) 14-20.

20. M.H.N. Beshaie, S.K. Habib, A.M. Yassin, G. Saad, and M.H. Hasab El-Naby, Cryst. Res. Technol., 34 (1999) 119-123.

21. R.J. McCabe and M.E. Fine, J. Electron. Mater. 31 (2002) 1276-1280.

22. Wade, K. Wu, J. Kuni, S. Yamada, and K. Miyahara J. Electron. Mater., 30 (2001) 1228-1232.

23. Dias Marcelino, Thiago A Costa, Bismarck L. Silva, Jose E. Speneli, Noe Cheung, Amauri Garcia. "A comparative analysis of micro structural features, tensile properties and wettability of hypo peritectic and peritectic Sn-Sb solder alloys", Microelectronics reliability, 81 (2018) 150-158.

24. B.A. Khalifa, R. Afify Ismail, A. M. Yassin, "Structure Analysis, Enhancement of Creep Resistance and Thermal Properties of Eutectic Sn-Ag Lead-Free Solder Alloy by Ti and Cd Additions", Journal of advance physics, 13, 8 (2017) 2347-2387.

25. E.A. Eid, A.N. Fouda, El-Shazly M. Duraia, "Effect of adding 0.5 wt\% ZnO nano particles, temperature and strain rate on tensile properties of Sn-5.0wt.\%Sb-0.5wt.\%Cu (SSC505) lead free solder alloy, Materials science \& Engineering A 657 (2016) 104 - 114.

26. Dias Marcelino, Thiago Costa, Otavio Rocha, Jose E. Spinelli, Noe Cheung, Amauri Garcia, "Interconnection of thermal parameters, Microstructure and mechanical properties in directionally solidified Sn-Sb lead free solder alloys" Materials Characterization, 106 (2015) 52-61.

27. M.M. El-Bahay, M.E. El-Mossalamy, M. Mahdy, and A.A. Bahgat, "Study of the Mechanical and Thermal Properties of Sn-5wt.\% Sb solder alloy at two annealing temperatures", Phy. Stat. Sol. (a) 198, No.1, (2003) 76-90.

28. M. Mathew, H. Yang, S. Movva, K. Murty, Metall. Mater. Trans. 36A (2005) 99 - 104. 